\title{
Reduction of nitrogen oxides by carbon monoxide over an iron oxide catalyst under dynamic conditions
}

\author{
Harvey Randall, Ralf Doepper, Albert Renken* \\ Institute of Chemical Engineering, Federal Institute of Technology, 1015 Lausanne, Switzerland \\ Received 6 July 1997; received in revised form 23 November 1997; accepted 2 December 1997
}

\begin{abstract}
The reduction of $\mathrm{NO}$ and $\mathrm{N}_{2} \mathrm{O}$ by $\mathrm{CO}$ over a silica-supported iron oxide catalyst was investigated by the transient response method, with different initial oxidation states of the catalyst, i.e. completely reduced $\left(\mathrm{Fe}_{3} \mathrm{O}_{4}\right)$, or oxidised $\left(\mathrm{Fe}_{2} \mathrm{O}_{3}\right)$. The influence of $\mathrm{CO}$ pre-adsorption was also studied. From the material balance on the gas phase species, it was shown that the composition of the catalyst changes during relaxation to steady-state. The degree of reduction of the catalyst at steady-state could thus be estimated. During the transient period, $\mathrm{CO}$ was shown to inhibit $\mathrm{N}_{2} \mathrm{O}$ as well as NO reductions by adsorption on reduced sites. The activity of the reduced catalyst was found to be substantially higher as compared to the oxidised catalyst for both reactions. On this basis, it was attempted to keep the catalyst in a reduced state by periodically reducing it with CO. As a result, a significant increase in the performance of the reactor with respect to steady-state operation could be achieved for $\mathrm{N}_{2} \mathrm{O}$ reduction by $\mathrm{CO}$. Finally, the dynamic behaviour of the $\mathrm{N}_{2} \mathrm{O}-\mathrm{CO}$ and $\mathrm{NO}-\mathrm{CO}$ reactions made it possible to evidence reaction steps, the occurrence of which could not be shown during our previous investigations on the separate interactions of the reactants with the catalyst. (C) 1998 Elsevier Science B.V. All rights reserved.
\end{abstract}

Keywords: Transient kinetics; Nitrogen oxides; Carbon monoxide; Oxide catalyst

\section{Introduction}

Amongst oxide catalysts, transition metal oxides are of particular interest for the reduction of NO by $\mathrm{CO}$, since they are the most active for this reaction [13]. On iron oxide, the reaction follows a consecutive reaction pathway wherein $\mathrm{NO}$ is first reduced to $\mathrm{N}_{2} \mathrm{O}$, which is then further reduced to $\mathrm{N}_{2}$ [4]:

$2 \mathrm{NO}+\mathrm{CO} \rightarrow \mathrm{N}_{2} \mathrm{O}+\mathrm{CO}_{2}$

$\mathrm{N}_{2} \mathrm{O}+\mathrm{CO} \rightarrow \mathrm{N}_{2}+\mathrm{CO}_{2}$

\footnotetext{
*Corresponding author. Tel.: 004121693 3181; fax: 004121 693 3190; e-mail: renken@igcsun3.epfl.ch
}

In previous works [4-6], we studied the interactions of $\mathrm{NO}, \mathrm{N}_{2} \mathrm{O}$ and $\mathrm{CO}$ individually with the catalyst. It was shown that $\mathrm{NO}$ readily reacts with the reduced catalyst $\left(\mathrm{Fe}_{3} \mathrm{O}_{4}\right)$. During this process (described in Eqs. (2) and (3)), $\mathrm{N}_{2} \mathrm{O}$ and $\mathrm{N}_{2}$ are formed by the reaction of $\mathrm{NO}$ and $\mathrm{N}_{2} \mathrm{O}$ with surface oxygen vacancies, symbolised by ( ). The catalyst is thus reoxidised to $\mathrm{Fe}_{2} \mathrm{O}_{3}$. (O) stands for oxygen from the lattice of iron oxide $[5,6]$. The formation of atomic oxygen species adsorbed on $\mathrm{Fe}_{2} \mathrm{O}_{3}, \mathrm{O}(\mathrm{O})$, according to Eq. (4), was also established. On the oxidised catalyst, $\mathrm{CO}$ is oxidised to $\mathrm{CO}_{2}$, and the catalyst is reduced to $\mathrm{Fe}_{3} \mathrm{O}_{4}$. $\mathrm{CO}$ was found to react with adsorbed oxygen species as well as oxygen from the lattice of iron oxide 
(Eqs. (5)-(7)) [5].

$$
\begin{aligned}
& 2 \mathrm{NO}+() \rightarrow \mathrm{N}_{2} \mathrm{O}+(\mathrm{O}) \\
& \mathrm{N}_{2} \mathrm{O}+\left(\mathrm{)} \rightarrow \mathrm{N}_{2}+(\mathrm{O})\right. \\
& \mathrm{N}_{2} \mathrm{O}+(\mathrm{O}) \rightarrow \mathrm{N}_{2}+\mathrm{O}(\mathrm{O}) \\
& \mathrm{CO}+\mathrm{O}(\mathrm{O}) \rightarrow \mathrm{CO}_{2}+(\mathrm{O}) \\
& \mathrm{CO}+(\mathrm{O}) \rightarrow \mathrm{CO}(\mathrm{O}) \\
& \mathrm{CO}(\mathrm{O}) \rightarrow \mathrm{CO}_{2}+()
\end{aligned}
$$

The aim of this work is to obtain more detailed information on the mechanism of the NO-CO reaction. For this purpose, we have applied the transient response method, which is suitable for heterogeneous catalytic reactions following a redox mechanism $[8,9]$. This method consists in creating a sharp change in gas phase composition at the reactor inlet, and measuring the responses of the gas phase components to this perturbation at the reactor outlet during relaxation to steady-state. From the qualitative analysis of the shapes of the responses of the products during the transient period, information on the rate-controlling step of product formation can be obtained [10,11]. Moreover, amounts of adsorbed intermediates can be determined [12]. Finally, changes in the catalyst composition can also be evidenced by this method, as shown for instance by Panayotov and Mehandjiev [9], who were able to determine the degree of reduction of $\mathrm{a} \mathrm{CuCo}_{2} \mathrm{O}_{4}$ catalyst at steady-state during the $\mathrm{NO}-\mathrm{CO}$ reaction.

In this work, we have applied the transient method to the $\mathrm{N}_{2} \mathrm{O}+\mathrm{CO}$ and the $\mathrm{NO}+\mathrm{CO}$ reactions. We found it important to investigate these reactions with different initial states of the catalyst, in order to obtain a maximum of mechanistic information. Hence, both reactions were carried out on initially reduced $\left(\mathrm{Fe}_{3} \mathrm{O}_{4}\right)$ and oxidised $\left(\mathrm{Fe}_{2} \mathrm{O}_{3}\right)$ catalysts. The influence of $\mathrm{CO}$ pre-adsorbed on the reduced catalyst was also investigated.

\section{Experimental}

\subsection{Gases and catalyst}

High purity gases were used ( $>99.99 \%$, except NO: $>99.9 \%$; Carbagas, Lausanne). Ar, which was used as the carrier gas, was further purified using a molecular sieve and an oxygen trap.
The catalyst consisted of $\mathrm{Fe}_{2} \mathrm{O}_{3}$ supported on $\mathrm{SiO}_{2}$ prepared by iron nitrate impregnation. The catalyst support, consisting of $\mathrm{SiO}_{2}$ particles $\left(200<d_{\mathrm{p}}<250 \mu \mathrm{m}\right.$, Grace GmbH, Worms) was impregnated in an aqueous solution of $\mathrm{Fe}\left(\mathrm{NO}_{3}\right)_{3}\left(1 \mathrm{kmol} / \mathrm{m}^{3}\right.$, $>99 \%$ pure, Fluka, Buchs). It was then dried under vacuum at room temperature, and finally calcinated at $650^{\circ} \mathrm{C}$. The amount of $\mathrm{Fe}$, determined by using a plasma emission spectrometer (Perkin-Elmer Plasma 2000, Le Mont-sur-Lausanne), after dissolution of the iron in concentrated hydrochloric acid $(38 \% \mathrm{HCl}$ at $60^{\circ} \mathrm{C}$ during $2 \mathrm{~h}$ ) was $10.4 \mathrm{wt} \% \mathrm{Fe}$. The specific area and pore size distribution, determined via Micromeretics (type ASAP 2000, Norcross, GA) was $S_{\mathrm{BET}}=252 \mathrm{~m}^{2} / \mathrm{g} .250 \mathrm{mg}$ of the catalyst were used during experiments.

\subsection{Apparatus}

The flow-apparatus used for step-response analysis basically consisted of two feed sections converging to a four-way valve, a fixed-bed, tubular, glass reactor (i.d.: $5 \mathrm{~mm}$ ) and a mass spectrometer (QMG 420, Balzers AG). It has previously been described in detail [4]. Due to adsorption of NO in the mass spectrometer, the concentration of NO was measured with an infrared analyser (Siemens AG, Karlsruhe).

\subsection{Procedures}

$\mathrm{CO}$ and $\mathrm{N}_{2}$ both generate an MS signal at $\mathrm{m} / \mathrm{z}$ $=28 \mathrm{amu}$. Moreover, $\mathrm{CO}_{2}$ and $\mathrm{N}_{2} \mathrm{O}$ give rise to an MS signal at $m / z=44 \mathrm{amu}$. In order to distinguish between these species, a mixture of ${ }^{13} \mathrm{CO},{ }^{12} \mathrm{CO}$ and $\operatorname{Ar}$ (1:4:95) was used (Alphagas, Paris). The concentration of all species could then be determined, since ${ }^{13} \mathrm{CO}$ generates an MS signal at $\mathrm{m} / z=29 \mathrm{amu}$, and the product ${ }^{13} \mathrm{CO}_{2}$ at $m / z=45 \mathrm{amu}$.

$\mathrm{N}_{2} \mathrm{O}+\mathrm{CO}$ as well as $\mathrm{NO}+\mathrm{CO}$ concentration steps were performed by substituting, at the reactor inlet, a flow of pure $\mathrm{Ar}$ (flow-rate: $100 \mathrm{ml}(\mathrm{NTP}) / \mathrm{min}$ ) with a flow containing $\mathrm{N}_{2} \mathrm{O}$ or $\mathrm{NO}$ and $\mathrm{CO}$ in $\mathrm{Ar}$ (same total pressure and flow-rate). Helium was always added to the feed containing the reactants as an inert tracer. The pressure in the reactor was $150 \mathrm{kPa}$. The inlet molar fraction of CO was always set to $y_{\mathrm{CO}, 0}=0.015$ (20\% of which was $\left.{ }^{13} \mathrm{CO}\right) . \mathrm{N}_{2} \mathrm{O}$ and $\mathrm{NO}$ inlet molar fractions 
were $y_{\mathrm{N}_{2} \mathrm{O}, 0}=0.004$ or 0.008 and $y_{\mathrm{NO}, 0}=0.004$, respectively.

Step experiments were performed with three different initial states of the catalyst, the preparations for which are described below.

\subsubsection{Reduced catalyst}

The catalyst was reduced in a flow of $\mathrm{CO}$ $\left(y_{\mathrm{CO}, 0}=0.015, T=310^{\circ} \mathrm{C}\right.$, flow-rate: $100 \mathrm{ml}(\mathrm{NTP}) /$ min) during $40 \mathrm{~min}$ (which assures total reduction to $\mathrm{Fe}_{3} \mathrm{O}_{4}$ as measured by the $\mathrm{X}$-ray diffraction patterns carried out on a Siemens D500 $(\theta / 2 \theta)$ diffractometer with $\mathrm{Cu} \mathrm{K} \mathrm{K}_{\alpha}$ monochromatic radiation [7]). Thereafter, the remaining $\mathrm{CO}$ adsorbed on the catalyst was desorbed in a flow of $\mathrm{Ar}$ at $450^{\circ} \mathrm{C}$ for $20 \mathrm{~min}$. The desorbing $\mathrm{CO}$ was monitored by MS during this procedure to ensure its complete removal.

\subsubsection{Reduced catalyst with adsorbed $C O$}

The catalyst was reduced in a flow of $\mathrm{CO}$ as in Section 2.3.1. Contrary to the preparation of the reduced catalyst, the remaining $\mathrm{CO}$ was not desorbed.

\subsubsection{Oxidised catalyst}

The catalyst was oxidised in a flow of $\mathrm{N}_{2} \mathrm{O}$ $\left(y_{\mathrm{N}_{2} \mathrm{O}, 0}=0.004, \quad T=310^{\circ} \mathrm{C}\right.$, flow-rate of $100 \mathrm{ml}$ (NTP)/min) during $40 \mathrm{~min}$ (which assures total oxidation to $\mathrm{Fe}_{2} \mathrm{O}_{3}$ as measured by the X-ray patterns [7]).

\section{Results and discussion}

\subsection{Reduction of $\mathrm{N}_{2} \mathrm{O}$ by $\mathrm{CO}$}

\subsubsection{Influence of the initial degree of reduction of the catalyst}

Fig. 1 shows the transient responses of the products to a step change in $\mathrm{N}_{2} \mathrm{O}$ and $\mathrm{CO}$ concentrations at $310^{\circ} \mathrm{C}$ over initially reduced and oxidised catalysts. Over the initially reduced catalyst, the $\mathrm{N}_{2}$ molar fraction instantaneously reaches its maximum potential value, namely $y_{\mathrm{N}_{2}}=0.004$ (corresponding to total conversion of $\mathrm{N}_{2} \mathrm{O}$ ) and, after approximately $500 \mathrm{~s}$, slowly decreases towards steady-state. The initial rise in $\mathrm{CO}_{2}$ concentration is slower than that for $\mathrm{N}_{2}$, due to the fact that surface oxidising species, which are not present at the beginning of the transient period, have to be formed through oxidation of the catalyst by $\mathrm{N}_{2} \mathrm{O}$ for

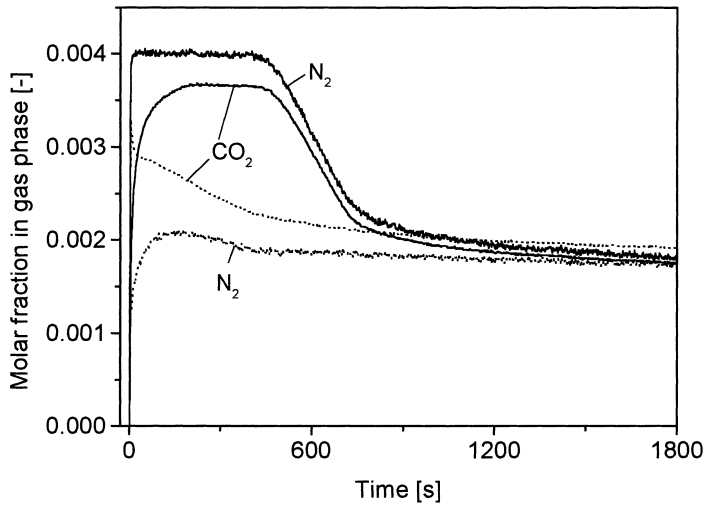

Fig. 1. Comparison between transient responses for the reduction of $\mathrm{N}_{2} \mathrm{O}$ by $\mathrm{CO}$ over initially reduced and oxidised catalysts. Conditions: $T=310^{\circ} \mathrm{C} ; y_{\mathrm{N}_{2} \mathrm{O}, 0}=0.004 ; y_{\mathrm{CO}, 0}=0.015$. Solid line: reduced catalyst; dots: oxidised catalyst.

$\mathrm{CO}$ oxidation to take place. The initial activity of the catalyst is higher than the activity at steady-state, since in the first part of the transient period, $\mathrm{CO}_{2}$ and $\mathrm{N}_{2}$ concentrations both go through a maximum. For times greater than $2000 \mathrm{~s}$, the concentrations of $\mathrm{CO}_{2}$ and $\mathrm{N}_{2}$ become almost equal, as expected from the material balance, since these products are formed in equimolar quantities during the $\mathrm{N}_{2} \mathrm{O}-\mathrm{CO}$ reaction. The $\mathrm{N}_{2}$ and $\mathrm{N}_{2} \mathrm{O}$ as well as the $\mathrm{CO}_{2}$ and $\mathrm{CO}$ responses were found to be complementary for all runs (i.e. the carbon and nitrogen mass balances were restricted to $\pm 1-2 \%$ ), indicating that no appreciable amounts of nitrogen or carbon containing species adsorb on the catalyst. The amount of $\mathrm{N}_{2}$ produced over the whole experiment is substantially higher than the amount of $\mathrm{CO}_{2}$ produced. Since no adsorption of reactants or products was observed, this indicates that the catalyst is reoxidised to some extent during the transient period, suggesting that the catalyst is more active when in a reduced state, since reoxidation occurs simultaneously, along with deactivation.

Over the initially oxidised catalyst, $\mathrm{CO}_{2}$ and $\mathrm{N}_{2}$ concentrations both show a maximum as a function of time, indicating a higher initial activity of the catalyst as compared to the steady-state. The maximum in $\mathrm{N}_{2}$ concentration is not reached instantaneously, indicating that surface-reducing species are produced in the first part of the transient period, through reduction of the catalyst by $\mathrm{CO}$. The amount of $\mathrm{CO}_{2}$ formed over the whole experiment is higher than the amount of $\mathrm{N}_{2}$. 
As for step changes on reduced catalysts, the amount of adsorbed $\mathrm{C}$ - and $\mathrm{N}$-containing species on initially oxidised catalysts was found to be negligible. Therefore, the difference between $\mathrm{CO}_{2}$ and $\mathrm{N}_{2}$ responses indicates that the catalyst has been reduced to some extent. The comparison between the responses of the oxidised and the reduced catalysts suggests that the reduced catalyst is more active, since higher average $\mathrm{CO}_{2}$ and $\mathrm{N}_{2}$ concentrations are obtained in this case. The higher activity observed for the reduced catalyst is in agreement with Mössbauer spectroscopic studies on the NO-CO reaction, by which it was shown that the reaction rate is proportional to the concentration of $\mathrm{Fe}^{2+}$ ions [13]. Moreover, by means of ESCA [14] and by applying the transient response method to the NO$\mathrm{CO}$ reaction on iron oxide [15], it was shown that the reduction of the catalyst is accompanied by an increase in activity.

The model in Eqs. (3)-(7) is consistent with the behaviour observed on initially oxidised catalysts. In this case, the maxima in $\mathrm{N}_{2}$ and $\mathrm{CO}_{2}$ responses is due to the fast redox reaction on the oxidised surface (Eqs. (4) and (5)), and relaxation towards steady-state at a lower activity arises from adsorption of $\mathrm{CO}$ on lattice oxygen (Eq. (6)). The model, however, does not account for the high initial activity encountered for initially reduced catalysts. The rate constant of Eq. (3) has to be rather small to describe the steady state, and therefore Eq. (3) cannot describe the fast initial rate. This behaviour can be explained by a fast redox reaction on reduced sites, ( ), by which a highly reactive surface oxygen species adsorbed on reduced sites is formed $(\mathrm{O}(\mathrm{)})$ ) (Eqs. (8) and (9)), which would be the precursor to the formation of lattice oxygen (Eq. (10)) - in this way, it is suggested that the oxidation of the catalyst (Eq. (3)) really takes place via a two step mechanism (Eqs. (8) and (10)).

$$
\begin{aligned}
& \mathrm{N}_{2} \mathrm{O}+\left(\mathrm{l} \rightarrow \mathrm{N}_{2}+\mathrm{O}()\right. \\
& \mathrm{O}(\mathrm{l})+\mathrm{CO} \rightarrow \mathrm{CO}_{2}+() \\
& \mathrm{O}(\mathrm{l}) \rightarrow(\mathrm{O})
\end{aligned}
$$

Such a precursor is known to exist in oxidation catalysis on solid oxides. For instance, Sokolovskii $[17,18]$ has proposed a generalised scheme of the catalytic oxidation, by which in a first step, gas phase oxygen forms highly reactive surface oxygen species which can be transformed into less reactive oxygen of the catalyst lattice. Adsorption of oxygen on a partially reduced surface may occur if there is only a partial charge transfer between the reduced surface cation to adsorbed oxygen or if the oxygen species occupies a site different from a surface lattice site [16].

The reactions in Eqs. (8)-(10), combined to reactions in Eqs. (4)-(7), are consistent with the gas phase responses to $\mathrm{N}_{2} \mathrm{O}+\mathrm{CO}$ concentration steps over initially reduced and oxidised catalysts. As a matter of fact, if reactions in Eqs. (8) and (9) are fast compared to the other reactions, the activity of the catalyst would be higher at the beginning of the transient period over the initially reduced catalyst with respect to the initially oxidised catalyst, as is observed experimentally. Over the initially reduced catalyst, $\mathrm{N}_{2}$ and $\mathrm{CO}_{2}$ responses would both go through a maximum at the beginning of the transient period, and subsequently decrease towards steady-state, due to the emergence of adsorbed oxygen into the lattice (reaction in Eq. (10)). The activity at steady-state depends on the ratio between the rates of consumption of $\mathrm{O}(\mathrm{)})$ by the two parallel reactions in Eqs. (9) and (10).

\subsubsection{Influence of $\mathrm{CO}$ pre-adsorption}

In Fig. 2, the transient responses of the products for step changes in $\mathrm{N}_{2} \mathrm{O}$ and $\mathrm{CO}$ concentration over reduced catalysts, with or without pre-adsorption of $\mathrm{CO}$, are compared. In both cases, there is a maximum in $\mathrm{N}_{2}$ and $\mathrm{CO}_{2}$ outlet molar fractions at the beginning

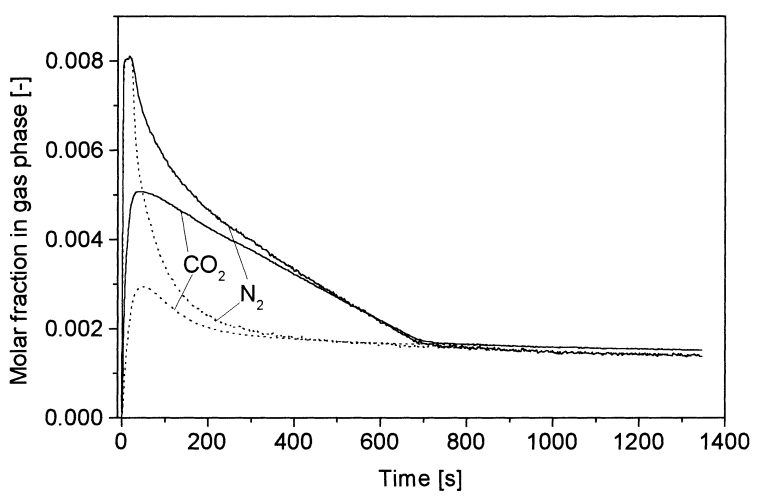

Fig. 2. Influence of $\mathrm{CO}$ pre-adsorption on the transient responses for the reduction of $\mathrm{N}_{2} \mathrm{O}$ by $\mathrm{CO}$ over initially reduced catalysts. Conditions: $T=290^{\circ} \mathrm{C} ; y_{\mathrm{N}_{2} \mathrm{O}, 0}=0.008 ; y_{\mathrm{CO}, 0}=0.015$. Solid line: reduced catalyst without pre-adsorbed $\mathrm{CO}$; dots: reduced catalyst with pre-adsorbed $\mathrm{CO}$. 

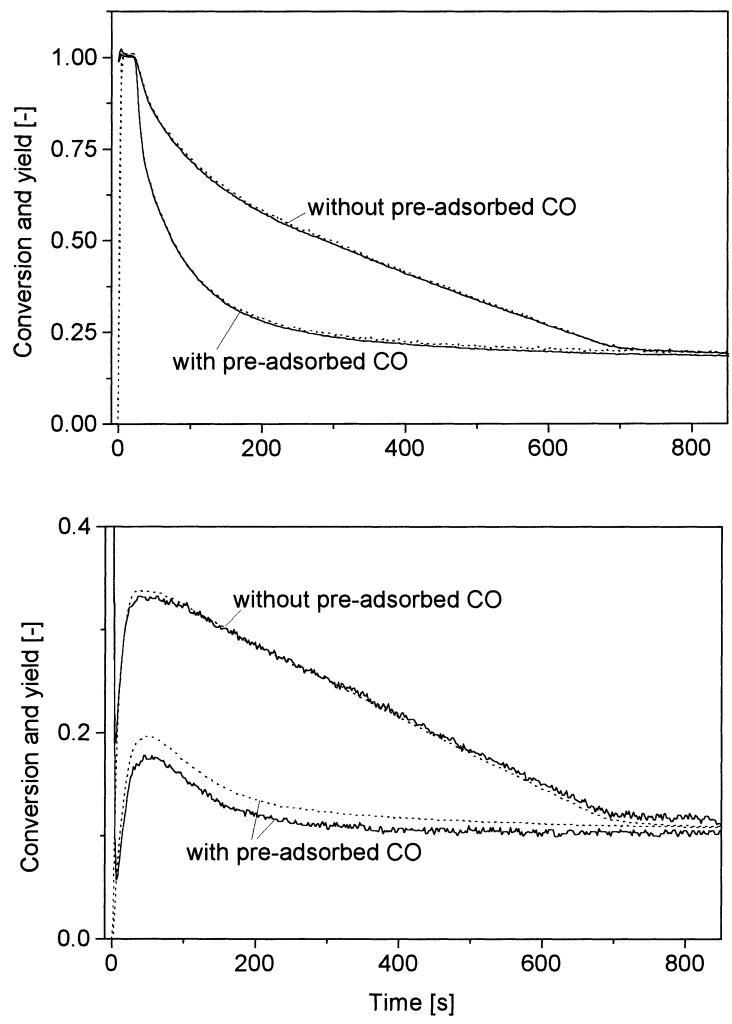

Fig. 3. Nitrogen and carbon balances during reduction of $\mathrm{N}_{2} \mathrm{O}$ by $\mathrm{CO}$ over reduced catalysts with and without pre-adsorbed $\mathrm{CO}$. Conditions: $T=290^{\circ} \mathrm{C} ; y_{\mathrm{N}_{2} \mathrm{O}, 0}=0.008 ; \mathrm{y}_{\mathrm{CO}, 0}=0.015$. Upper graph: $\mathrm{N}_{2} \mathrm{O}$ conversion (solid line) and $\mathrm{N}_{2}$ yield (dots); lower graph: $\mathrm{CO}$ conversion (solid line) and $\mathrm{CO}_{2}$ yield (dots).

of the transient followed by relaxation to steady-state at lower values of outlet molar fraction. However, the effect of CO pre-adsorption is to decrease the activity of the catalyst during relaxation to steady-state: during this period, the average transient $\mathrm{CO}_{2}$ and $\mathrm{N}_{2}$ concentrations are lower than that for the catalyst without pre-adsorption of $\mathrm{CO}$, indicating an inhibiting effect of $\mathrm{CO}$.

Fig. 3 gives the conversions and yields of reactants and products referred to inlet $\mathrm{N}_{2} \mathrm{O}$ and $\mathrm{CO}$ molar fractions (Eqs. (11), (12), (13) and (14)) for both experiments. The mean residence time of an inert gas in the reactor was found to be equal to $6 \mathrm{~s}$ [4], so that conversions and yields were considered only for times greater than $6 \mathrm{~s}$, in order to eliminate hydrodynamic effects on conversions and yields.

$$
\begin{aligned}
& X_{\mathrm{N}_{2} \mathrm{O}}=1-\frac{y_{\mathrm{N}_{2} \mathrm{O}}}{y_{\mathrm{N}_{2} \mathrm{O}, 0}}, \\
& X_{\mathrm{CO}}=1-\frac{y_{\mathrm{CO}}}{y_{\mathrm{CO}, 0}}, \\
& Y_{\mathrm{N}_{2}}=\frac{y_{\mathrm{N}_{2}}}{y_{\mathrm{N}_{2} \mathrm{O}, 0}}, \\
& Y_{\mathrm{CO}_{2}}=\frac{y_{\mathrm{CO}_{2}}}{y_{\mathrm{CO}, 0}} .
\end{aligned}
$$

For both catalyst pre-treatments, the conversion of $\mathrm{N}_{2} \mathrm{O}$ is equal to the yield of $\mathrm{N}_{2}$, indicating that $\mathrm{N}_{2} \mathrm{O}$ does not adsorb on the catalyst. For the catalyst without pre-adsorbed $\mathrm{CO}$, the conversion of $\mathrm{CO}$ is equal to $\mathrm{CO}_{2}$ yield, i.e., $\mathrm{CO}$ adsorption on the initially reduced catalyst is not observed. Upon pre-adsorbing $\mathrm{CO}, \mathrm{CO}_{2}$ yield is higher than $\mathrm{CO}$ conversion, due to the consumption of pre-adsorbed $\mathrm{CO}$ during the transient response.

The inhibiting effect of $\mathrm{CO}$ can be explained by adsorption of $\mathrm{CO}$ on reduced sites:

$\mathrm{CO}+() \rightarrow \mathrm{CO}()$

As a result, the concentration of reduced sites, ( ), at the beginning of the transient response is lower in the case of $\mathrm{CO}$ pre-adsorption, leading to a lower activity during relaxation to steady-state, as compared to the initially reduced catalyst without pre-adsorbed CO. Consumption of adsorbed $\mathrm{CO}$ by $\mathrm{N}_{2} \mathrm{O}$ (Eq. (16)) restores surface oxygen vacancies, such as, whether the activity at steady-state is the same, whether $\mathrm{CO}$ is pre-adsorbed or not. The reaction in Eq. (16) accounts for the fact that $\mathrm{CO}_{2}$ yield is higher than $\mathrm{CO}$ conversion during the $\mathrm{N}_{2} \mathrm{O}+\mathrm{CO}$ concentration steps on reduced catalysts with pre-adsorbed $\mathrm{CO}$ (Fig. 3).

$\mathrm{N}_{2} \mathrm{O}+\mathrm{CO}() \rightarrow \mathrm{N}_{2}+\mathrm{CO}_{2}+($ )

Evidence for the occurrence of reactions in Eqs. (15) and (16) has been shown previously by comparing the transient responses of initially reduced catalysts with and without pre-adsorbed $\mathrm{CO}$ to $\mathrm{N}_{2} \mathrm{O}$ concentration steps [4].

\subsubsection{Average degree of reduction of catalyst at steady-state}

As seen in the previous sections for step changes in $\mathrm{N}_{2} \mathrm{O}$ and $\mathrm{CO}$ concentration over oxidised and reduced catalysts with or without $\mathrm{CO}$ pre-adsorption, the relative amounts of $\mathrm{N}_{2}$ and $\mathrm{CO}_{2}$ produced during relaxa- 
tion to steady-state were found to be substantially different. The difference between $\mathrm{CO}_{2}$ and $\mathrm{N}_{2}$ responses was used to estimate the average degree of reduction of the catalyst at steady-state $\left(\phi_{\mathrm{ss}}\right.$, Eq. (17)), which corresponds to the ratio between the average concentration of reduced sites at steadystate and the total concentration of sites $\left(N_{\mathrm{s}}\right)$. $\phi_{\mathrm{ss}}$ thus determined from the $\mathrm{CO}_{2}$ and $\mathrm{N}_{2}$ molar fractions at the reactor outlet corresponds to an average value, since there is a gradient in $\mathrm{N}_{2} \mathrm{O}$ and $\mathrm{CO}$ concentrations in the reactor, generating a gradient of the degree of reduction of the catalyst as well. The total concentration of sites $\left(N_{\mathrm{s}}\right)$ has been previously determined by measuring the amounts of $\mathrm{N}_{2}$ and $\mathrm{CO}_{2}$ formed, respectively, upon oxidising the reduced catalyst with $\mathrm{N}_{2} \mathrm{O}$ and reducing the oxidised catalyst with $\mathrm{CO}$ [7]. An experimental value of $N_{\mathrm{s}}=0.33 \mathrm{~mol} / \mathrm{kg}_{\text {cat }}$ was obtained. The loading of the catalyst was $10.4 \%$, calculated on $\mathrm{Fe}$, as measured by atomic absorption. Therefore, $250 \mathrm{mg}$ of catalyst contain $26 \mathrm{mg} \mathrm{Fe}$, that equals $0.466 \mathrm{mmol}$ Fe. The catalyst contains $0.698 \mathrm{mmol} \mathrm{O}$ in the case of $\mathrm{Fe}_{2} \mathrm{O}_{3}$ and $0.621 \mathrm{mmol}$ $\mathrm{O}$ in the case of $\mathrm{Fe}_{3} \mathrm{O}_{4}$. The difference is $0.078 \mathrm{mmol}$, that becomes $0.31 \mathrm{~mol} / \mathrm{kg}$. The difference with the observed $0.33 \mathrm{~mol} / \mathrm{kg}$ is in the range of experimental error.

$\phi_{\mathrm{ss}}= \begin{cases}1-\frac{\frac{\dot{n}_{\mathrm{TOT}}}{m_{\mathrm{cat}}} \int_{0}^{\infty}\left(y_{\mathrm{N}_{2}}-y_{\mathrm{CO}_{2}}\right) \mathrm{dt}}{N_{\mathrm{s}}} & \text { (reduced catalyst) } \\ \frac{\dot{n}_{\mathrm{TOT}}}{m_{\mathrm{cat}}} \int_{0}^{\infty}\left(y_{\mathrm{CO}_{2}}-y_{\mathrm{N}_{2}}\right) \mathrm{dt} & \text { (oxidised catalyst). } \\ N_{\mathrm{s}} & \end{cases}$

Fig. 4 gives the degree of reduction of the catalyst at steady-state at different temperatures and inlet molar ratios $M\left(M=y_{\mathrm{CO}, 0} / y_{\mathrm{N}_{2} \mathrm{O}, 0}\right)$ for initially reduced catalysts with or without pre-adsorbed CO. Almost the same values of $\phi_{\mathrm{ss}}$ are obtained at $M=1.88$ for reduced catalysts with and without $\mathrm{CO}$ pre-adsorption. Thus, despite the different transient responses obtained for these initial states of the catalyst (Fig. 2) the same values of conversions, yields and reduction state of the catalyst are obtained at steady-state. With an inlet molar ratio of $M=3.75$, higher values of $\phi_{\mathrm{ss}}$ are obtained, which is reasonable, since in that case the concentration of the gas phase reducing species (CO) is increased with respect to the oxidising species $\left(\mathrm{N}_{2} \mathrm{O}\right)$.

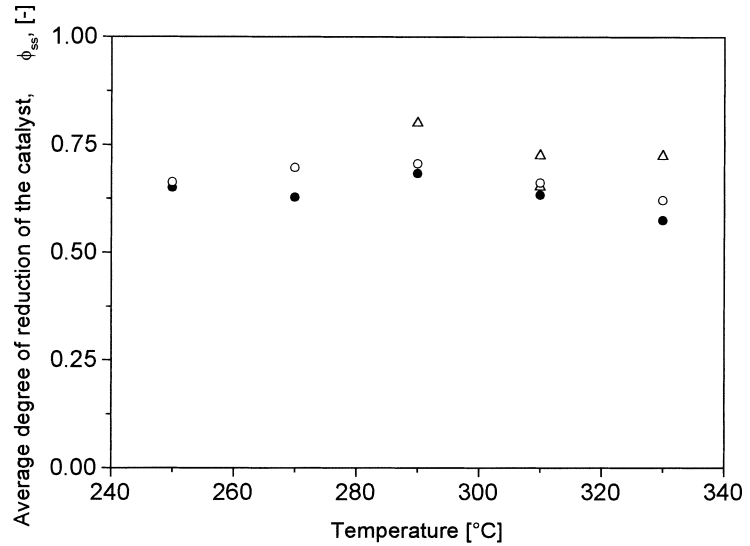

Fig. 4. Average degree of reduction of the catalyst at steady-state as a function of temperature for different values of the inlet molar ratio $M=\mathrm{CO} / \mathrm{N}_{2} \mathrm{O}:(\Delta) M=3.75$, reduced catalyst, no pre-adsorbed $\mathrm{CO}$; (O) $M=1.88$, reduced catalyst, no pre-adsorbed $\mathrm{CO}$; $M=1.88$, reduced catalyst, pre-adsorbed CO.

The values of $\phi_{\text {ss }}$ for the initially oxidised catalysts could not be determined, due to the fact that experiments with initially oxidised catalysts were stopped before $\mathrm{CO}_{2}$ and $\mathrm{N}_{2}$ concentrations attained equal values, owing to the high price of ${ }^{13} \mathrm{CO}$ (longer relaxation times are obtained with these catalysts).

In general, under the reported experimental conditions, the catalyst is rather reduced at steady-state $\left(\phi_{\mathrm{ss}}>0.6\right)$. There is no significant effect of temperature on $\phi_{\mathrm{ss}}$, indicating that the values of the activation energies of reduction and oxidation of the catalyst are close to each other. This result is in accordance with previous studies on the reduction of hematite by $\mathrm{CO}$ [6] and oxidation of magnetite by $\mathrm{N}_{2} \mathrm{O}$ [5]. As a matter of fact, reduction of hematite was shown to proceed through a three-step mechanism, the energies of activation of which are 75,73 and $88 \mathrm{~kJ} / \mathrm{mol}$. For the oxidation of magnetite, a value of $72 \mathrm{~kJ} / \mathrm{mol}$ was obtained, which is close to the values obtained for the reduction of the catalyst.

\subsubsection{Reduction of $\mathrm{N}_{2} \mathrm{O}$ by $\mathrm{CO}$ under periodic conditions}

In the previous section, it was shown that the reduced catalyst has a higher activity for the reduction of $\mathrm{N}_{2} \mathrm{O}$ by $\mathrm{CO}$ than the oxidised catalyst. On this basis, it was attempted to keep the catalyst in a reduced state 


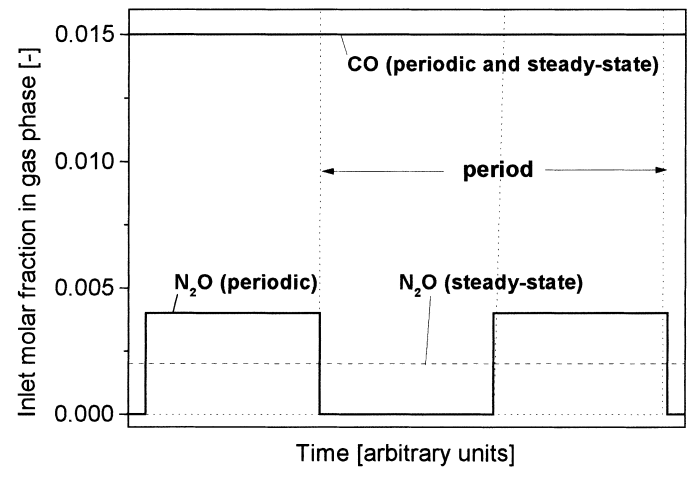

Fig. 5. Inlet molar fractions as a function of time for periodic and steady-state operation.

by periodically substituting the feed containing $\mathrm{N}_{2} \mathrm{O}$ and $\mathrm{CO}$ with a feed containing only $\mathrm{CO}$. Furthermore, this periodic situation was compared to steady-state operation, where $\mathrm{CO}$ and $\mathrm{N}_{2} \mathrm{O}$ inlet molar fractions were set to the time-average molar fractions applied during periodic operation. This is depicted in Fig. 5, where the inlet molar fractions of $\mathrm{N}_{2} \mathrm{O}$ and $\mathrm{CO}$ for periodic and steady-state operation as a function of time are shown.

During periodic experiments, the half-period under $\mathrm{N}_{2} \mathrm{O}$ and $\mathrm{CO}$ was always set equal to the half-period under $\mathrm{CO}$. The total period was varied between 32 and $4320 \mathrm{~s}$. The dynamic responses of reactants and products at cycle-invariance for two different periods (a short and a long period) are given in Fig. 6. During the half-cycle under $\mathrm{CO}, \mathrm{CO}_{2}$ is still produced, due to reduction of the catalyst. At the lower period of $32 \mathrm{~s}$, during the period under $\mathrm{N}_{2} \mathrm{O}$ and $\mathrm{CO}, \mathrm{N}_{2} \mathrm{O}$ conversion rapidly decreases due to an insufficient reduction time under $\mathrm{CO}$. On the other hand, at the higher period of $720 \mathrm{~s}$, during the $\mathrm{N}_{2} \mathrm{O}+\mathrm{CO}$ half-cycle, $\mathrm{N}_{2} \mathrm{O}$ is totally converted during approximately $80 \mathrm{~s}$, but reaches a higher concentration at the end of the half-cycle than that noted for the lower period of $32 \mathrm{~s}$.

In Fig. 7, the time-average reactor performance with respect to reactants and products over several periods at cycle-invariance, as calculated with Eqs. (18), (19), (20) and (21), are compared to the values obtained at steady-state. These reactor performances correspond to the time-average molar flow rates of products and of converted reactants, respectively.
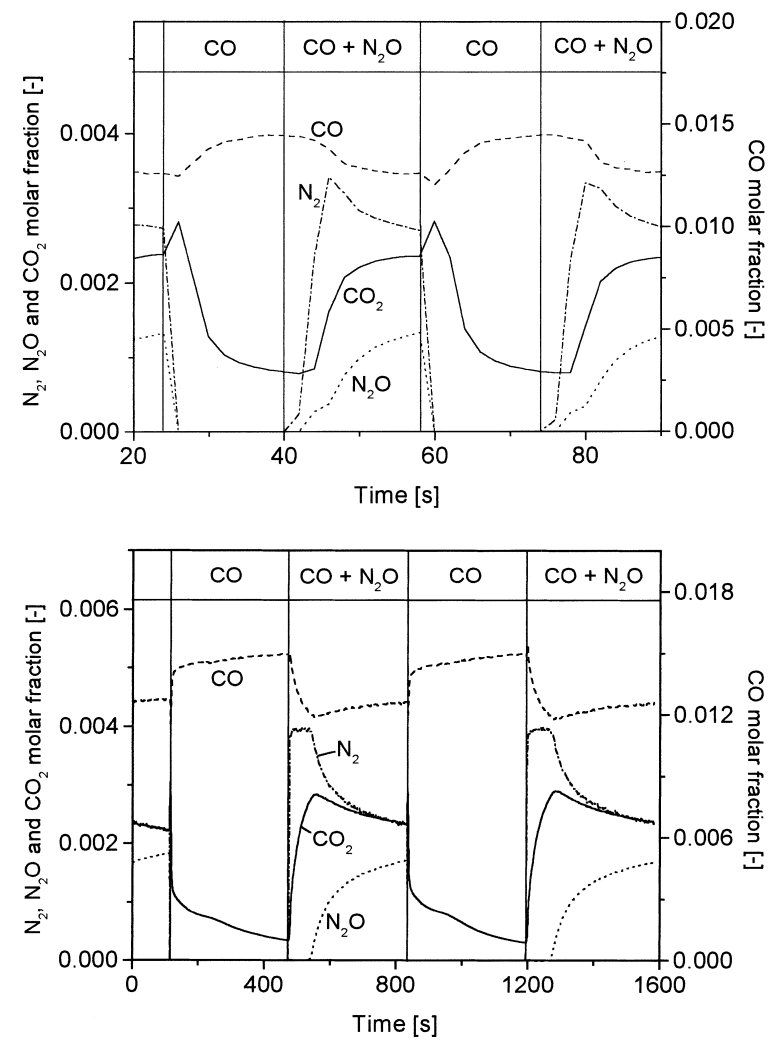

Fig. 6. Reduction of $\mathrm{N}_{2} \mathrm{O}$ by $\mathrm{CO}$ under periodic inlet conditions at cycle-invariance. Conditions: $T=310^{\circ} \mathrm{C}$; upper graph: period $=32 \mathrm{~s}$; lower graph: period $=720 \mathrm{~s}$.

$L_{\mathrm{p}, \mathrm{N}_{2}}=\dot{n}_{\mathrm{TOT}} \overline{y_{\mathrm{N}_{2}}}$,

$L_{\mathrm{p}, \mathrm{N}_{2} \mathrm{O}}=\dot{n}_{\mathrm{TOT}}\left(\overline{y_{\mathrm{N}_{2} \mathrm{O}, 0}}-\overline{y_{\mathrm{N}_{2} \mathrm{O}}}\right)$,

$L_{\mathrm{p}, \mathrm{CO}_{2}}=\dot{n}_{\mathrm{TOT}} \overline{y_{\mathrm{CO}_{2}}}$,

$L_{\mathrm{p}, \mathrm{CO}}=\dot{n}_{\mathrm{TOT}}\left(\overline{y_{\mathrm{CO}, 0}}-\overline{y_{\mathrm{CO}}}\right)$,

where $\overline{y_{\mathrm{N}_{2}}}, \overline{y_{\mathrm{N}_{2} \mathrm{O}}}, \overline{y_{\mathrm{CO}_{2}}}$ and $\overline{y_{\mathrm{CO}}}$ are the time-average molar fractions during periodic operation, whereas $\overline{y_{\mathrm{N}_{2} \mathrm{O}, 0}}$ and $\overline{y_{\mathrm{CO}, 0}}$ represent the average inlet molar fractions of the reactants (see Fig. 5).

As can be seen in Fig. 7, concentration cycling with short periods of about 30-60 s led to an increase in reactor performance with respect to $\mathrm{N}_{2} \mathrm{O}$, and $\mathrm{N}_{2}$ yield of approximately $30 \%$, which presumably arises from a higher time-average degree of reduction of the catalyst as compared to the steady-state situation. The values at quasi steady-state (QSS), i.e. for an infinite period $[19,20]$, were calculated as follows: at 

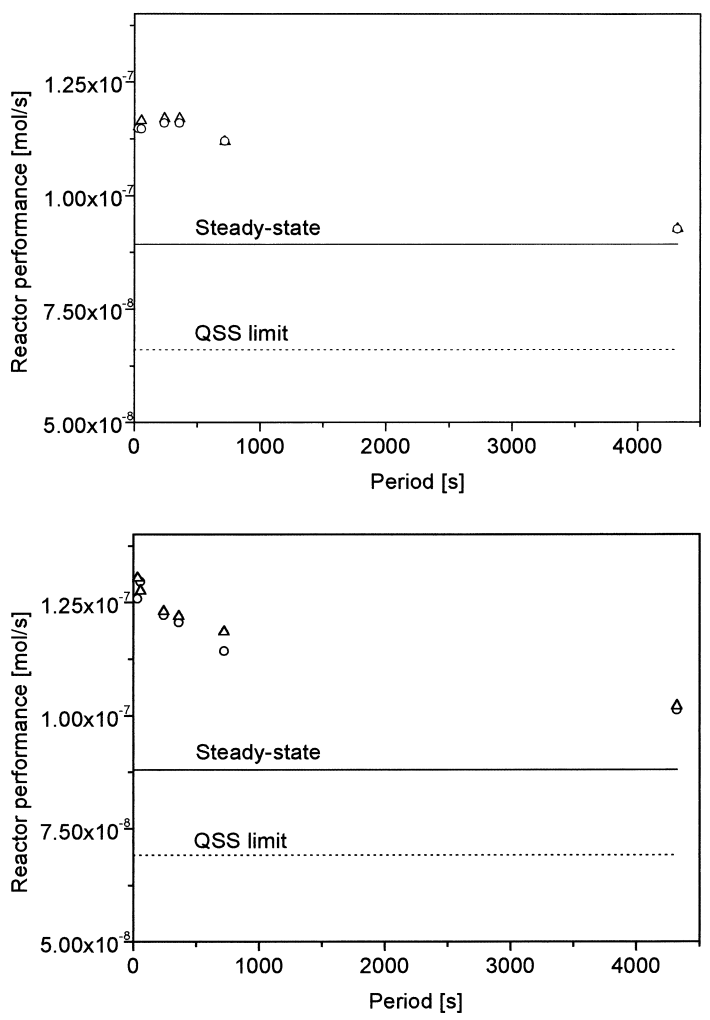

Fig. 7. Time-average reactor performance as a function of period. Comparison between periodic operation and steady-state. Upper graph: $\mathrm{N}_{2} \mathrm{O}(\mathrm{O})$ and $\mathrm{N}_{2}(\Delta)$; lower graph: $\mathrm{CO}(\mathrm{O})$ and $\mathrm{CO}_{2}(\Delta)$.

QSS, the transient period (which lasts less than two hours) can be neglected with respect to the period at steady-state (an infinite time), so that the time-average molar fractions of the reactants and products correspond to half of their values at steady-state during the half-period under $\mathrm{N}_{2} \mathrm{O}+\mathrm{CO}$, since during the halfperiod under $\mathrm{CO}$, the average molar fractions are equal to 0 . That the QSS limit is lower than the steady-state ensures that the observed increase in reactor performance is not due to any concentration effect but is actually due to an oxidation state of the catalyst which cannot be achieved under steady-state conditions.

\subsection{Reduction of $\mathrm{NO}$ by $\mathrm{CO}$}

\subsubsection{Influence of the initial degree of reduction of the catalyst}

Fig. 8 shows the transient response of the reduced catalyst to a step change in NO and $\mathrm{CO}$ con-
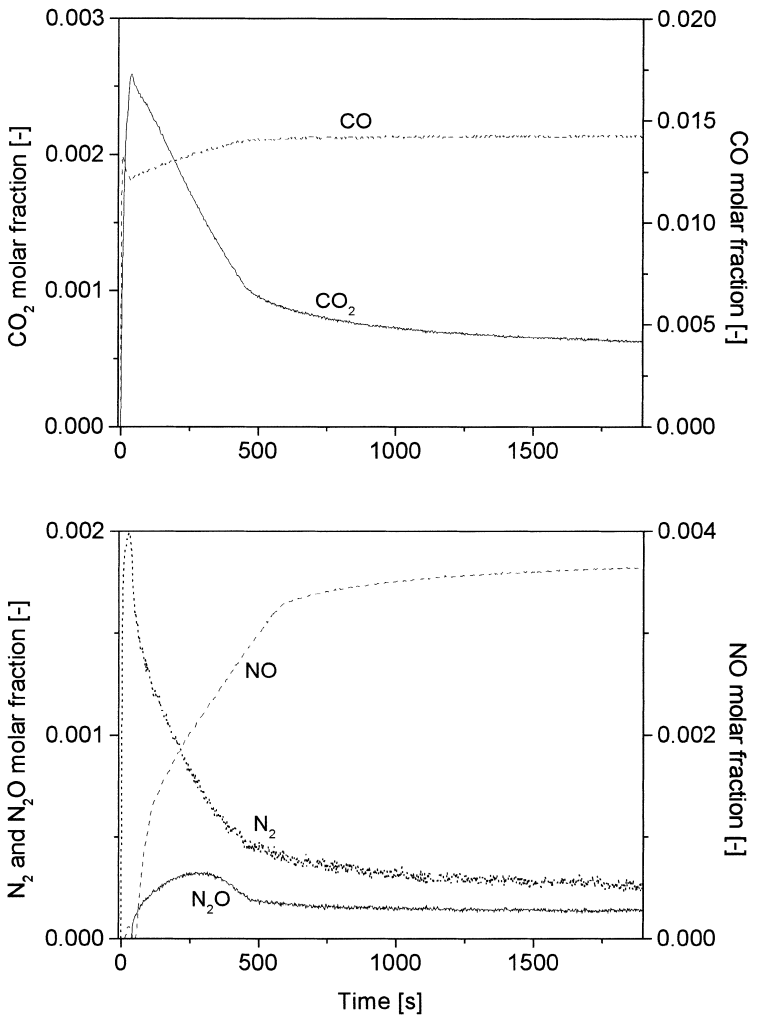

Fig. 8. Transient responses for the reduction of $\mathrm{NO}$ by $\mathrm{CO}$ over an initially reduced catalyst. Conditions: $T=310^{\circ} \mathrm{C} ; y_{\mathrm{NO}, 0}=0.004$; $y_{\mathrm{CO}, 0}=0.015$.

centrations at $310^{\circ} \mathrm{C} . \mathrm{N}_{2}, \mathrm{~N}_{2} \mathrm{O}$ as well as $\mathrm{CO}_{2}$ molar fractions all go through a maximum at the beginning of the transient response, indicating that the initial state of the catalyst has a higher activity as compared to steady-state. The maximum in $\mathrm{N}_{2} \mathrm{O}$ concentration is delayed with respect to $\mathrm{N}_{2}$. This phenomena has already been observed in a previous work on oxidation of magnetite with NO [4], and was attributed to the consecutive reduction of $\mathrm{NO}$ to $\mathrm{N}_{2}$, with $\mathrm{N}_{2} \mathrm{O}$ as the intermediate product by reaction of $\mathrm{NO}$ and $\mathrm{N}_{2} \mathrm{O}$ with reduced surface sites and simultaneous oxidation of the surface (Eqs. (2) and (3)).

The following dynamic material balances (nitrogen and carbon balances) were applied to calculate $\mathrm{CO}$ and $\mathrm{NO}$ molar fractions from inlet $\mathrm{CO}$ and $\mathrm{NO}$ molar fractions as well as from $\mathrm{CO}_{2}, \mathrm{~N}_{2} \mathrm{O}$ and $\mathrm{N}_{2}$ outlet 
molar fractions.

$y_{\mathrm{CO}, \mathrm{mb}}=F y_{\mathrm{CO}, 0}-y_{\mathrm{CO}_{2}}$,

$y_{\mathrm{NO}, \mathrm{mb}}=\left[\Delta_{\mathrm{N}}\right]_{\mathrm{IR}}$,

where

$\Delta_{\mathrm{N}}=F y_{\mathrm{NO}, 0}-2\left(y_{\mathrm{N}_{2} \mathrm{O}}+y_{\mathrm{N}_{2}}\right)$.

$F$ represents the experimental cumulative residence time distribution function ( $F$-curve) of the catalytic reactor, i.e. the response of the reactor to a concentration step input function of an inert tracer ( $\mathrm{He}$ in our case) normalised by dividing the output concentration by the inlet concentration of the tracer [21]. In the right term of Eq. (23), in square brackets, appears the difference between $F y_{\mathrm{NO}, 0}$ and the molar fraction of nitrogen atoms in the products, $\Delta_{\mathrm{N}}$, as measured by mass spectrometry. The subscript IR in the right term of Eq. (23) means that $\Delta_{\mathrm{N}}$ was transformed into the values of $\Delta_{\mathrm{N}}$ that would be measured in the infra-red analyser, in order to compare NO molar fraction thus calculated $\left(y_{\mathrm{NO}, \mathrm{mb}}\right)$ to $\mathrm{NO}$ molar fraction measured at the same place, i.e. in the infra-red analyser. This transformation was performed by using $\Delta_{\mathrm{N}}$ as inlet function to the infra-red analyser, and by solving the dynamic material equations describing the hydrodynamics of the infra-red analyser, which leads to $\left[\Delta_{\mathrm{N}}\right]_{\mathrm{IR}}$. Fig. 9 shows that the responses of $\mathrm{NO}$ and CO calculated from Eqs. (22) and (23) are almost superimposed to the measured responses, indicating that no notable adsorption of carbon- or nitrogen-containing species takes place on the reduced catalyst.

At steady-state, for the NO-CO reaction, the following relation exists between $\mathrm{CO}_{2}, \mathrm{~N}_{2}$ and $\mathrm{N}_{2} \mathrm{O}$ molar fractions:

$y_{\mathrm{CO}_{2}, \mathrm{mb}}=y_{\mathrm{N}_{2} \mathrm{O}}+2 y_{\mathrm{N}_{2}}$.

In Fig. 9, it can be seen that during the first $1000 \mathrm{~s}$ approximately, the molar fraction of $\mathrm{CO}_{2}$ calculated according to Eq. (25) is higher than the experimental response of $\mathrm{CO}_{2}$. Since adsorption of C- or N-containing species is not observed, this effect indicates that the catalyst has been oxidised to some extent during the transient period. As for the reduction of $\mathrm{N}_{2} \mathrm{O}$ by $\mathrm{CO}$ (previous section), oxidation of the catalyst occurs simultaneously, along with deactivation, indicating that the catalyst has a higher activity when reduced.

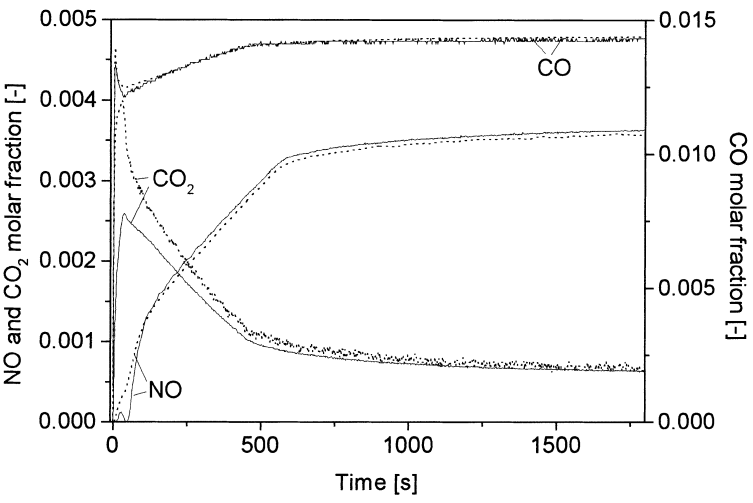

Fig. 9. Transient carbon and nitrogen balances for the reduction of $\mathrm{NO}$ by $\mathrm{CO}$ over an initially reduced catalyst. Conditions: $T=310^{\circ} \mathrm{C} ; y_{\mathrm{NO}, 0}=0.004 ; y_{\mathrm{CO}, 0}=0.015$. Solid line: measured; dots: calculated from material balance.

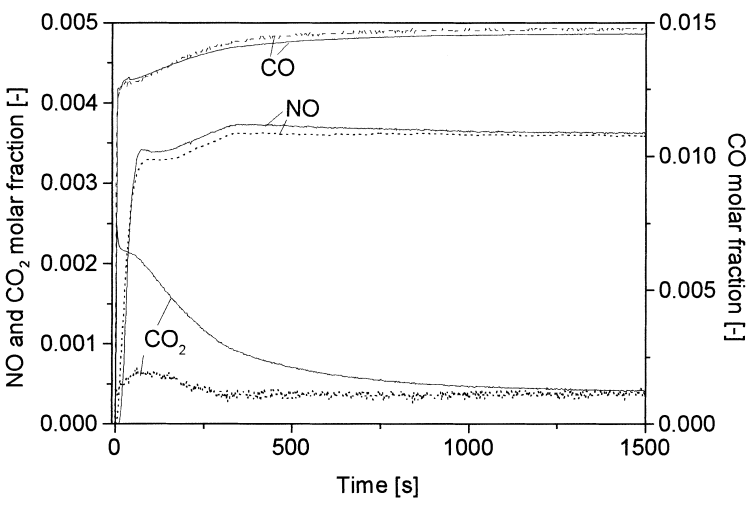

Fig. 10. Transient carbon and nitrogen balances for the reduction of $\mathrm{NO}$ by $\mathrm{CO}$ over an initially oxidised catalyst. Conditions: $T=310^{\circ} \mathrm{C} ; y_{\mathrm{NO}, 0}=0.004 ; y_{\mathrm{CO}, 0}=0.015$. Solid line: measured; dots: calculated from material balance.

In Fig. 10, the $\mathrm{CO}$, $\mathrm{NO}$ and $\mathrm{CO}_{2}$ responses calculated from Eqs. (22), (23) and (25) are compared to the measured responses for a step change in $\mathrm{NO}$ and $\mathrm{CO}$ concentrations at $310^{\circ} \mathrm{C}$ over an oxidised catalyst. $\mathrm{CO}_{2}$ molar fractions measured and calculated from Eq. (25) show a maximum at the beginning of the experiment, indicating a higher activity of the catalyst in its initial state. Thereafter, the molar fractions of products decrease towards steady-state. The slight differences between experimental and calculated $\mathrm{CO}$ and $\mathrm{NO}$ responses lie within the uncertainty range for $\mathrm{NO}$ and $\mathrm{CO}$ concentrations $( \pm 5 \%)$, so that adsorp- 
tion of CO or NO can be considered negligible. During the first $1000 \mathrm{~s}$ approximately, the calculated response of $\mathrm{CO}_{2}$ is lower than the measured response of $\mathrm{CO}_{2}$. Since $\mathrm{C}$ and $\mathrm{N}$ adsorption do not occur to an appreciable extent, this indicates that the catalyst has been reduced during this period. The activity of the oxidised catalyst is considerably lower than that for the reduced catalyst, as can be seen by comparing Figs. 9 and 10: the molar fractions of all products are higher at the beginning of the transient response for the initially reduced catalyst than for the initially oxidised catalyst.

\subsubsection{Influence of $\mathrm{CO}$ pre-adsorption on reduced catalysts}

In Fig. 11, the transient responses of the products $\left(\mathrm{CO}_{2}, \mathrm{~N}_{2} \mathrm{O}\right.$ and $\left.\mathrm{N}_{2}\right)$ to a step-change in $\mathrm{NO}$ and $\mathrm{CO}$
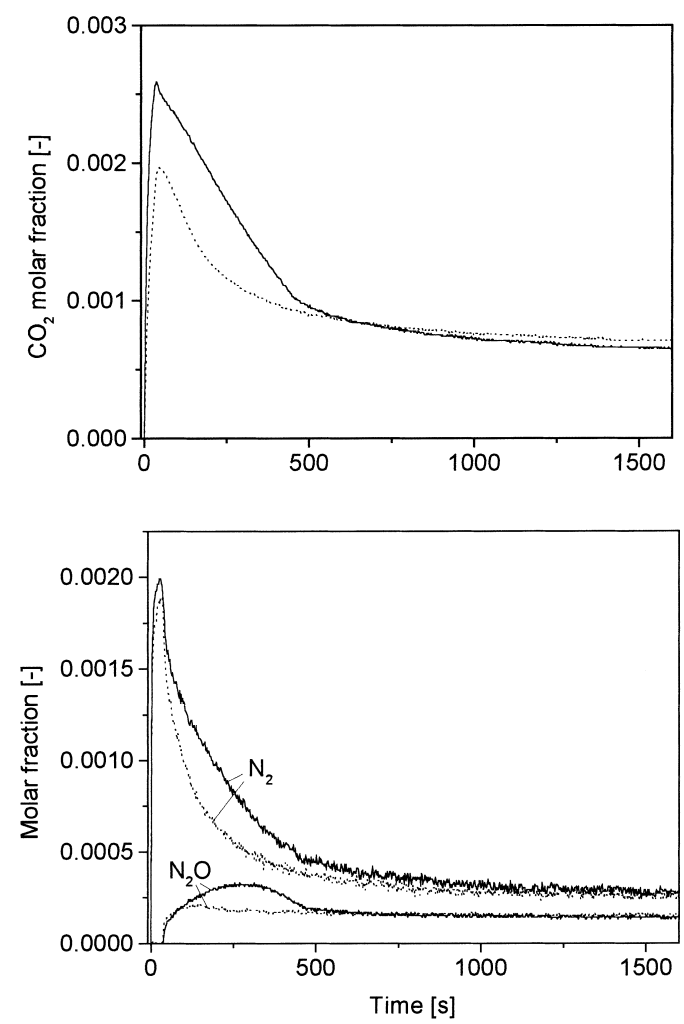

Fig. 11. Transient responses of products for the reduction of NO by $\mathrm{CO}$ over initially reduced catalysts with and without pre-adsorbed CO. Conditions: $T=310^{\circ} \mathrm{C} ; y_{\mathrm{NO}, 0}=0.004 ; y_{\mathrm{CO}, 0}=0.015$. Solid line: reduced catalyst without preadsorbed $\mathrm{CO}$; dots: reduced catalyst with preadsorbed $\mathrm{CO}$. concentrations at $310^{\circ} \mathrm{C}$ for initially reduced catalysts with and without pre-adsorbed $\mathrm{CO}$ are compared. As for the reduction of $\mathrm{N}_{2} \mathrm{O}$ by $\mathrm{CO}$, the effect of $\mathrm{CO}$ preadsorption is to decrease the activity of the catalyst during relaxation to steady-state: the molar fractions of the products during this period are lower upon preadsorbing $\mathrm{CO}$. However, the same molar fractions are obtained at steady-state. Again, inhibition by $\mathrm{CO}$ can be explained by adsorption of $\mathrm{CO}$ on reduced sites (reaction in Eq. (15)); consumption of adsorbed CO by $\mathrm{N}_{2} \mathrm{O}$ (reaction in Eq. (16)) accounts for the fact that activity at steady-state does not depend on $\mathrm{CO}$ preadsorption.

\subsubsection{Average degree of reduction of catalyst at steady-state}

As seen in the previous sections, the degree of reduction of the catalyst changes during relaxation to steady-state, whether the catalyst is initially reduced or oxidised. Thus, the average degree of reduction of the catalyst at steady-state $\left(\phi_{\mathrm{ss}}\right)$ was calculated for all experimental conditions, according to Eq. (25).

$\phi_{\mathrm{ss}}=\left\{\begin{array}{cc}1-\frac{\frac{\dot{n}_{\mathrm{TOT}}}{m_{\mathrm{cat}}} \int_{0}^{\infty}\left(2 y_{\mathrm{N}_{2}}+y_{\mathrm{N}_{2} \mathrm{O}}-y_{\mathrm{CO}_{2}}\right) \mathrm{dt}}{N_{\mathrm{s}}} & \text { (reduced catalyst), } \\ \frac{\dot{n}_{\mathrm{TOT}}}{m_{\mathrm{cat}}} \int_{0}^{\infty}\left(y_{\mathrm{CO}_{2}}-2 y_{\mathrm{N}_{2}}-y_{\mathrm{N}_{2} \mathrm{O}}\right) \mathrm{dt} & \text { (oxidised catalyst). } \\ N_{\mathrm{s}} & \text {. }\end{array}\right.$

The results are given in Fig. 12 for the three investigated temperatures and initial states of the catalyst. For initially reduced catalysts, the values obtained for $\phi_{\mathrm{ss}}$ are the same, whether $\mathrm{CO}$ is pre-adsorbed or not. At $T=340^{\circ} \mathrm{C}, \phi_{\mathrm{ss}}$ for the initially oxidised catalyst is close to the values obtained for reduced catalysts. At the lower temperatures, $\phi_{\mathrm{ss}}$ for the initially oxidised catalyst could not be determined, due to the fact that experiments were stopped before the steady-state was reached, owing to the high price of ${ }^{13} \mathrm{CO}$ (longer relaxation times are observed for the initially oxidised catalyst).

Under the investigated reaction conditions, the catalyst, at steady-state, is almost reduced $\left(\phi_{\mathrm{ss}} \cong 0.85\right)$, and $\phi_{\mathrm{ss}}$ is independent of temperature, indicating that the apparent activation energies for reduction and oxidation of the catalyst are comparable.

By comparing Fig. 12 with Fig. 4, it appears that with same molar ratio in the feed (i.e., $M=3.75) \phi_{\mathrm{ss}}$ is 


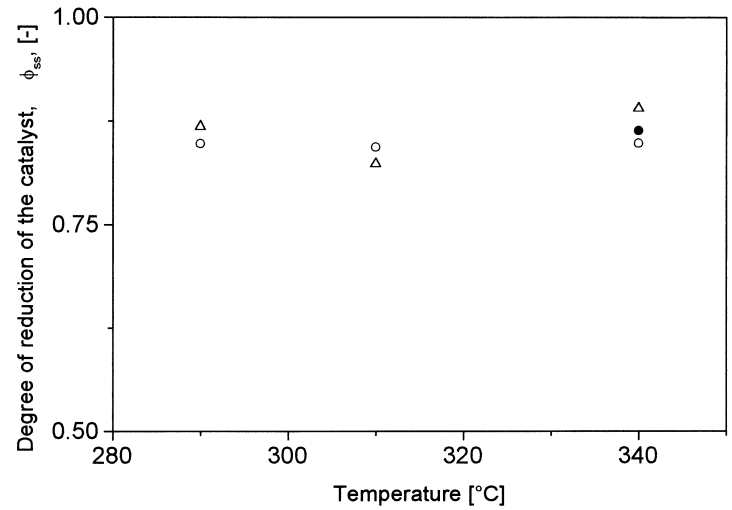

Fig. 12. Average degree of reduction of the catalyst at steady-state as a function of temperature for different initial states of the catalyst for the NO-CO reaction: $(\Delta)$ reduced catalyst, no preadsorbed $\mathrm{CO}$; $(\mathrm{O})$ reduced catalyst, preadsorbed $\mathrm{CO}$; oxidised catalyst.

higher for the $\mathrm{NO}-\mathrm{CO}$ reaction than for the $\mathrm{N}_{2} \mathrm{O}-\mathrm{CO}$ reaction, suggesting that the rate of oxidation of the catalyst by NO is lower than the rate of oxidation of the catalyst by $\mathrm{N}_{2} \mathrm{O}$. This observation is consistent with our previous kinetic investigations on the reduction of $\mathrm{NO}$ and $\mathrm{N}_{2} \mathrm{O}$ with $\mathrm{CO}$ under steady-state conditions [4,7], during which it was found that the rate constant for surface oxidation by $\mathrm{NO}$ is lower than the rate constant for surface oxidation by $\mathrm{N}_{2} \mathrm{O}$.

The main features of the transient responses during the reduction of $\mathrm{NO}$ by $\mathrm{CO}$ are essentially the same as those for the reduction of $\mathrm{N}_{2} \mathrm{O}$ by $\mathrm{CO}$ : the catalyst is more active when in a reduced state, there is an inhibition by $\mathrm{CO}$ and the catalyst is rather reduced at steady-state. The following reaction mechanism (which, in addition to the elementary steps proposed in the previous section for the $\mathrm{N}_{2} \mathrm{O}-\mathrm{CO}$ reaction, includes two additional steps for $\mathrm{NO}$ reduction, i.e. reactions in Eqs. (2) and (27) is consistent with the observations made during the investigation of $\mathrm{N}_{2} \mathrm{O}+\mathrm{CO}$ and $\mathrm{NO}+\mathrm{CO}$ reactions:

\section{Reduction of the catalyst:}

$$
\begin{aligned}
& \mathrm{CO}+\mathrm{O}(\mathrm{O}) \rightarrow \mathrm{CO}_{2}+(\mathrm{O}) \\
& \mathrm{CO}+(\mathrm{O}) \rightarrow \mathrm{CO}(\mathrm{O}) \\
& \mathrm{CO}(\mathrm{O}) \rightarrow \mathrm{CO}_{2}+() \\
& \mathrm{CO}+\mathrm{O}() \rightarrow \mathrm{CO}_{2}+()
\end{aligned}
$$

Oxidation of the catalyst:

$$
\begin{aligned}
& 2 \mathrm{NO}+() \rightarrow \mathrm{N}_{2} \mathrm{O}+\mathrm{O}() \\
& \mathrm{N}_{2} \mathrm{O}+() \rightarrow \mathrm{N}_{2}+\mathrm{O}() \\
& \mathrm{O}() \rightarrow(\mathrm{O}) \\
& 2 \mathrm{NO}+(\mathrm{O}) \rightarrow \mathrm{N}_{2} \mathrm{O}+\mathrm{O}(\mathrm{O}) \\
& \mathrm{N}_{2} \mathrm{O}+(\mathrm{O}) \rightarrow \mathrm{N}_{2}+\mathrm{O}(\mathrm{O})
\end{aligned}
$$

$\mathrm{CO}$ adsorption on reduced sites:

$\mathrm{CO}+() \rightarrow \mathrm{CO}()$

Consumption of adsorbed $\mathrm{CO}$ :

$\mathrm{N}_{2} \mathrm{O}+\mathrm{CO}() \rightarrow \mathrm{N}_{2}+\mathrm{CO}_{2}+($ )

The fast redox reaction on the reduced surface in Eqs. (9) and (2) explains the high initial activity observed for $\mathrm{NO}+\mathrm{CO}$ concentration steps on initially reduced catalysts (Fig. 8). Deactivation by emergence of adsorbed oxygen into the lattice (Eq. (10)) leads to a lower activity at steady-state. The higher initial activity with respect to steady-state observed on initially oxidised catalysts (Fig. 10) can be explained by the occurrence of the redox reaction on the oxidised surface in Eqs. (5) and (27). The following decrease in activity is due to $\mathrm{CO}$ adsorption on lattice oxygen (Eq. (7)), which leads to a lower activity at steadystate, since CO reactive desorption (Eq. (7)) is slower than the reaction between $\mathrm{CO}$ and excess oxygen (Eq. (5)). The inhibiting effect of $\mathrm{CO}$, which has been evidenced by comparing the initial activities during $\mathrm{NO}+\mathrm{CO}$ concentration steps on initially reduced catalysts with and without pre-adsorbed CO (Fig. 11), can be explained by the adsorption of $\mathrm{CO}$ on reduced sites (Eq. (15)), which leads to lower rates of reactions in Eqs. (9) and (2). The consumption of adsorbed CO (Eq. (16)) explains that the same activity and selectivity are reached as steady-state, whether $\mathrm{CO}$ is preadsorbed or not.

\section{Conclusions}

By investigating the reduction of $\mathrm{N}_{2} \mathrm{O}$ and $\mathrm{NO}$ by $\mathrm{CO}$ under transient conditions, it was shown that the composition of the catalyst changes during relaxation to steady-state, where it reaches a rather reduced state, close to $\mathrm{Fe}_{3} \mathrm{O}_{4}$. The activity of the reduced catalyst $\left(\mathrm{Fe}_{3} \mathrm{O}_{4}\right)$ for both reactions was found to be signifi- 
cantly higher than the activity at steady-state. This phenomenon was explained by a fast redox reaction of $\mathrm{N}_{2} \mathrm{O}$, NO and $\mathrm{CO}$ on the reduced surface, involving atomic oxygen species adsorbed on reduced surface sites. Periodic operation of the catalytic reactor resulted in a substantial increase in the performance of the reactor with respect to the steady-state situation for the $\mathrm{N}_{2} \mathrm{O}-\mathrm{CO}$ reaction. This effect is presumably due to the achievement of higher time-average degrees of reduction of the catalyst. The activity of the catalyst oxidised by $\mathrm{N}_{2} \mathrm{O}$ is higher than the activity at steadystate for $\mathrm{N}_{2} \mathrm{O}-\mathrm{CO}$ and $\mathrm{NO}-\mathrm{CO}$ reactions, due to the redox reaction of $\mathrm{N}_{2} \mathrm{O}, \mathrm{NO}$ and $\mathrm{CO}$ on the oxidised surface, involving excess surface oxygen, i.e. atomic oxygen species adsorbed on oxidised surface sites. $\mathrm{CO}$ was shown to inhibit both reactions by adsorption on reduced sites. Finally, the present study made it possible to evidence reaction steps, the occurrence of which could not be shown during our previous investigations [4-7] on the separate interactions of the reactants with the catalyst.

\section{Nomenclature}

$d_{\mathrm{p}} \quad$ diameter of particles (m)

$F \quad$ cumulative residence time distribution function ( $F$-curve) of the catalytic reactor

$L_{\mathrm{p}, j} \quad$ reactor performance with respect to species $j(\mathrm{~mol} / \mathrm{s})$

$M \quad$ molar ratio in feed

$m_{\text {cat }} \quad$ amount of catalyst $(\mathrm{kg})$

$\mathrm{m} / \mathrm{z} \quad$ specific mass (amu)

$n_{\mathrm{TOT}} \quad$ total molar flow rate $(\mathrm{mol} / \mathrm{s})$

$N_{\mathrm{s}} \quad$ total concentration of sites $(=0.33 \mathrm{~mol} /$ $\left.\mathrm{kg}_{\text {cat }}[7]\right)$

NTP normal conditions of temperature and pressure $\left(0^{\circ} \mathrm{C}, 1.013 \times 10^{5} \mathrm{~Pa}\right)$

$S_{\text {BET }} \quad$ BET specific area of catalyst $\left(\mathrm{m}^{2} / \mathrm{g}\right)$

$T \quad$ temperature $(\mathrm{K})$

$y \quad$ molar fraction

$\overline{y_{j}} \quad$ time-average molar fraction for species $j$

$y_{j} \quad$ molar fraction in gas phase for species $j$

$y_{j, 0} \quad$ molar fraction in feed for species $j$

( ) lattice oxygen vacancy

(O) lattice oxygen

$\mathrm{O}(\mathrm{O}) \quad$ oxygen adsorbed on oxidised site

$\mathrm{O}(\mathrm{)} \quad$ oxygen adsorbed on reduced site
$\mathrm{CO}(\mathrm{O}) \quad \mathrm{CO}$ adsorbed on oxidised site

$\mathrm{CO}(\mathrm{)} \quad \mathrm{CO}$ adsorbed on reduced site

Greek letters

$\phi \quad$ degree of reduction of the catalyst

$\begin{array}{ll}\text { Subscripts } \\ 0 & \text { inlet } \\ \mathrm{IR} & \begin{array}{l}\text { at outlet from infra-red analyser } \\ \text { index for gas phase species }\left(\mathrm{CO}, \mathrm{CO}_{2}, \mathrm{~N}_{2},\right.\end{array} \\ j & \left.\mathrm{~N}_{2} \mathrm{O}\right) \\ \mathrm{mb} & \text { calculated from material balance } \\ \mathrm{ss} & \text { steady-state }\end{array}$

\section{Acknowledgements}

We are grateful to the Swiss National Science Foundation for providing financial support to this research.

\section{References}

[1] G.Z. Gasan-Zade, M.Y. Sultanov, T.G. Alkhazov, React. Kinet. Catal. 7 (1977) 397.

[2] G.Z. Gasan-Zade, T.K. Mukherjee, T.G. Alkhazov, React. Kinet. Catal. 12 (1979) 525.

[3] G.L. Bauerle, G.R. Service, K. Nobe, Eng. Chem. Prod. Res. Develop. 11 (1972) 54.

[4] H. Randall, R. Doepper, A. Renken, Can. J. Chem. Eng. 74 (1996) 586.

[5] H. Randall, R. Doepper, A. Renken, Catal. Today 31(1) (1997) 13.

[6] H. Randall, R. Doepper, A. Renken, Ind. Eng. Chem. Res. 36(8) (1997) 2996.

[7] H. Randall, Ph.D. Thesis, Ecole Polytechnique Fédérale de Lausanne, Switzerland, 1996.

[8] D. Panayotov, M. Khristova, D. Mehandjiev, Appl. Catal. 34 (1987) 49.

[9] D. Panayotov, D. Mehandjiev, Appl. Catal. 34 (1987) 65.

[10] M. Kobayashi, Chem. Eng. Sci. 37 (1982) 393.

[11] M. Kobayashi, Chem. Eng. Sci. 37 (1982) 403.

[12] H. Kobayashi, M. Kobayashi, Catal. Rev. Sci. Eng. 10 (1974) 139.

[13] D.V. Sokolskii, G.K. Alekseeva, A.S. Khlystov, V.I. Yaskhevich, G.N. Kotova, React. Kinet. Catal. Lett. 6 (1977) 59.

[14] K. Sakurai, Y. Okamoto, T. Imanaka, S. Teranishi, Bull. Chem. Soc. Jpn. 49 (1976) 1732.

[15] G.Z. Gasan-Zade, T.N. Mirgavanov, T.G. Alkhazov, Kinet. Katal. 32 (1991) 1488. 
[16] H.H. Kung, in: B. Delmon, J.T. Yates (Eds.), Studies in Surface Science and Catalysis, vol. 45, Elsevier, Amsterdam, 1989, pp. 111 and 153.

[17] V.D. Sokolovskii, React. Kinet. Catal. Lett. 35 (1987) 337.

[18] V.D. Sokolovskii, Catal. Rev. Sci. Eng. 32 (1990) 1.
[19] P. Silveston, R.R. Hudgins, A. Renken, Catal. Today 25 (1995) 91.

[20] D.T. Lynch, Can. J. Chem. Eng. 64 (1986) 1035.

[21] O. Levenspiel, Chemical Reaction Engineering, 2nd ed., Wiley, New York, 1972, pp 253-265. 